\title{
Presentation, Management Practices and In-hospital Outcomes of Patients with Acute Coronary Syndrome in a Tertiary Cardiac Centre in Bangladesh
}

\author{
Fathima Aaysha Cader ${ }^{1}$, M. Maksumul Haq ${ }^{2}$, Sahela Nasrin, ${ }^{3}$ C.M. Shaheen Kabir ${ }^{4}$
}

\begin{abstract}
Background: There is no large-scale data on the management practices and in-hospital outcomes of acute coronary syndromes (ACS) in Bangladesh. This study aimed to document the presentation characteristics, treatment practices and in-hospital outcomes of ACS patients presenting to a specialized tertiary cardiac care institute in Bangladesh.

Methods: This retrospective observational study included all ACS patients presenting to Ibrahim Cardiac Hospital \& Research Institute (ICHRI), Dhaka, Bangladesh, over the period of January 2013 to December 2013. Data were collected from hospital discharge records and catheterization laboratory database, and analysis was carried out using Statistical Package for Social Sciences (SPSS) version 16.0 (Chicago, Illinois, USA).

Result: A total of 1914 ACS patients were included. The mean age was $57.8 \pm 12.1$ years. $71.4 \%$ were male. $39.8 \%$ presented with ST-elevation myocardial infarction (STEMI), $39.7 \%$ with non-ST-elevation myocardial infarction (NSTEMI) and $20.5 \%$ presented with unstable angina (UA). $68.91 \%$ were diabetic, $74.24 \%$ hypertensive, $53.23 \%$ were dyslipidaemic, $25.75 \%$ were smokers and $20.72 \%$ had chronic kidney disease (CKD).1022 (53.4\%)
\end{abstract}

of all admitted ACS patients underwent coronary angiography, among whom $649(33.9 \%)$ were advised percutaneous coronary intervention ( $\mathrm{PCI})$, and 198 $(10.3 \%)$ and $207(10.8 \%)$ were advised coronary artery bypass graft (CABG) surgery and medical management respectively. $\mathrm{PCI}$ was performed in 509 patients $(26.6 \%)$ during the index admission. The majority of these patients were those of STEMI $(39.23 \%)$, among whom $47(6.2 \%)$ underwent primary $\mathrm{PCl} .146(7.6 \%)$ of the patients presenting with ACS expired during hospital stay. Mortality was highest among STEMI (10.5\%), followed by NSTEMI (8.3\%) and UA (1\%). 501 (26.2\%) patients developed left ventricular failure, $108(5.6 \%)$ patients developed shock and 265 (13.8\%) developed acute kidney injury.

Conclusion: This study represents one of the larger single-centre analyses of ACS patients in Bangladesh thus far. Our patients have high prevalence of cardiovascular risk factors, particularly diabetes and hypertension. There is room for further improvement in terms of guideline-directed medical and interventional treatment modalities, in order to improve outcomes.

Key words: Acute coronary syndrome, Outcomes, Bangladesh.

(Bangladesh Heart Journal 2017; 32(2) : 106-113)

Introduction

Cardiovascular disease (CVD) is a growing epidemic in South Asia, and is the leading cause of mortality in the Indian subcontinent ${ }^{1}$, as well as Bangladesh ${ }^{2}$. Acute coronary syndromes (ACS) are responsible for a large number of emergency hospital admissions and mortality, and represent the principal form of clinical presentation of coronary artery disease (CAD). Estimates from the Global Burden of Disease Study suggest that the South Asian region will have more

1. Assistant Registrar, Cardiology, Ibrahim Cardiac Hospital \& Research Institute, Dhaka, Bangladesh.

2. Professor \& Head, Department of Cardiology, Ibrahim Cardiac Hospital \& Research Institute, Dhaka, Bangladesh.

3. Assistant Professor, Department of Cardiology, Ibrahim Cardiac Hospital \& Research Institute, Dhaka, Bangladesh.

4. Assistant Professor, Department of Cardiology, Ibrahim Cardiac Hospital \& Research Institute, Dhaka, Bangladesh.

Correspondence to: Dr. Fathima Aaysha Cader, Assistant Registrar, Cardiology, Ibrahim Cardiac Hospital \& Research Institute, Dhaka, Bangladesh. Email: aaysha.cader@gmail.com, Tel: +880174-9419893

DOI: http://dx.doi.org/10.3329/bhj.v32i2.36097

Copyright (c) 2017 Bangladesh Cardiac Society. Published by Bangladesh Cardiac Society. This is an Open Access articles published under the Creative Commons Attribution-NonCommercial 4.0 International License (CC BY-NC). This license permits use, distribution and reproduction in any medium, provided the original work is properly cited and is not used for commercial purposes. 
individuals with atherothrombotic cardiovascular disease than any other region by the year $2020^{1}$. Most notable features of CAD in South Asian populations are extreme prematurity, increased severity, hospitalization and mortality 2,3 .

The current understanding of the aetiology of ACS involves plaque erosion or rupture in response to inflammation, leading to local occlusive or non-occlusive thrombus ${ }^{4}$. Depending on the degree and reversibility of this dynamic obstruction, the clinical manifestations of ACS comprise a continuous spectrum of risk that progresses from unstable angina (UA) to non-ST-segment elevation myocardial infarction (NSTEMI) and ST-segment elevation myocardial infarction (STEMI) ${ }^{5}$.

A number of national and multi-national registries across the globe, including in Asia, have investigated the clinical characteristics and treatment-related outcomesamong ACS patients ${ }^{6-26}$. These data have shown regional variation in the clinical presentations, use of invasive procedures and outcomes across the spectrum of ACS, across different regions of the world.In the South Asian region, two large registries in India ${ }^{7-8}$ have documented the demographic characteristics, treatment practices and outcomes of ACS patients.

There are limited data onthe presentation and outcomes of ACS from Bangladesh, with most of the studies being small ones, restricted to a particular subset of ACS patients ${ }^{27-}$

${ }^{29}$.A large-scale ACS registry of Bangladeshi patients is a timely necessity. This study aimed to document the characteristics, treatment practices and outcomes of ACS patients presenting to a tertiary cardiac care institute in Bangladesh.

\section{Methods}

Patient population and definitions: This was a crosssectional retrospective analysis of all patients who presented with the diagnosis of ACS to Ibrahim Cardiac Hospital \& Research Institute (ICHRI), Dhaka, Bangladesh. All consecutive patients with a final diagnosis of ACS comprising of either STEMI, NSTEMI and UA were included in the study. Diagnosis of the different types of ACS and definitions of data variables and outcomes were based on ACCF/ AHA data standards ${ }^{30}$.

Data collection: Demographic characteristics, risk factors, baseline clinical parameters, treatment modalities and medication administered, angiographic profiles, revascularization techniques and in-hospital outcomes were documented on a case report form (CRF) by study investigators. Data were derived from hospital in-patient clinical notes, discharge summaries and cardiac catheterization laboratory database.
Statistical analysis: Data analyses were carried out using Statistical Package for Social Sciences(SPSS) version 16.0 (Chicago, Illinois, USA). Continuous variables were expressed as mean \pm standard deviation, and compared using the Student's t-test and ANOVA statistics. Categorical variables were expressed as number with corresponding percentage, and compared using the chi-square test.A $p$ value $<0.05$ was considered statistically significant.

Ethical approval: The study complied with the Declaration of Helsinki and ethical approval was obtained by the ethical review committee of ICHRI, Dhaka, Bangladesh.

\section{Results}

Demographic characteristics, key risk factors, and clinical presentation

A total 5502 patients were admitted during the period from January 2013 to December 2013, of whom 1914 (34.8\%) presented withACS.The demographic details and baseline patient characteristics are presented in Table 1. The mean age of participants was $57.8 \pm 12.1$ (range 21-97) years. The majority of the patients $(51.7 \%)$ were between the ages of 45- 64 years, with $17.1 \%<45$ years of age. 1366 patients(71.4\%) were male. Almost equal numbers of patients presented with STEMI and NSTEMI (39.8\% and 39.7\% respectively). 392 (20.5\%) patients presented with UA. Diabetes (68.91\%), hypertension $(74.24 \%)$ and dyslipidaemia $(53.23 \%)$ were the leading risk factors for CAD. Smoking and stroke were more common among patients with STEMI $(p<0.001)$. Diabetes, prior myocardial infarction (MI) and chronic kidney disease (CKD)were significantly more frequent among those presenting with NSTEMI, while prior percutaneous coronary intervention $(\mathrm{PCl})$, prior coronary artery bypass graft (CABG) surgery and hypertension were more common among those presenting with UA $(p<0.001)$. $79.5 \%$ of patients had positive cardiac biomarkers at presentation. $79.1 \%$ of patients presented with chest pain, a symptom which was approximately equally observed across the whole spectrum of ACS, albeit slightly lesser among those with NSTEMI (42.3\%). However, NSTEMIpatients tended to present the most frequently with dyspnoea $(42.3 \%)$ in comparison with STEMI (24.5\%) and UA patients (28.3\%). This was reflected further by the increased incidence of left ventricular failure (31.9\%) seen among NSTEMI patients.

\section{In-hospital diagnostic evaluations and management} 1022 (53.4\%) of the 1914 admitted ACS patients underwent coronary angiography during index hospitalisation.Left main stenosis $>50 \%$ and severe graft vessel stenosis was observed significantly more among NSTEMI patients $(3.4 \%$ and $1.3 \%$ respectively, $p<0.001)$. Significant stenosis of left anterior descending (LAD) and right coronary artery (RCA) were seen most frequently among STEMI patients (Table 2). 
Table-I

Patient level characteristics in presentation, by ACS type

\begin{tabular}{|c|c|c|c|c|c|}
\hline Parameter & TotalN (\%) & STEMIn (\%) & NSTEMIn (\%) & UAn (\%) & p value \\
\hline Total ACS patients & 1914 & $762(39.8)$ & $760(39.7)$ & $392(20.5)$ & \\
\hline \multicolumn{6}{|l|}{ Demographics } \\
\hline Age, years & $57.8 \pm 12.1$ & $55.6 \pm 11.8$ & $60.2 \pm 12.2$ & $57.9 \pm 11.6$ & $<0.001$ \\
\hline$<45$ & $327(17.1)$ & $172(22.5)$ & $97(12.8)$ & $58(21.2)$ & $<0.001$ \\
\hline $45-64$ & $989(51.7)$ & $401(52.6)$ & $378(49.8)$ & $210(53.6)$ & \\
\hline $65-74$ & $382(20)$ & $125(16.4)$ & 174(22.9) & $83(21.2)$ & \\
\hline e"75 & $216(11.3)$ & $65(8.5)$ & $110(14.5)$ & $41(10.5)$ & \\
\hline Sex: male gender & $1366(71.4)$ & $587(77.1)$ & $525(69.0)$ & $254(64.8)$ & $<0.001$ \\
\hline BMI & $25.6 \pm 3.7$ & $25.4 \pm 3.6$ & $25.6 \pm 3.8$ & $26.2 \pm 3.9$ & 0.033 \\
\hline Admitted on holidays & $123(6.4 \%)$ & $48(6.3)$ & $46(6.0)$ & $29(7.4)$ & 0.664 \\
\hline \multicolumn{6}{|l|}{ Key Risk factors } \\
\hline Diabetes & $1319(68.91)$ & $495(65.0)$ & $556(73.3)$ & $267(68.1)$ & 0.003 \\
\hline Hypertension & $1421(74.24)$ & $518(68.1)$ & $590(77.5)$ & $313(79.8)$ & $<0.001$ \\
\hline Tobacco/Smoking & $493(25.75)$ & 256(33.6) & $166(21.8)$ & 71(18.1) & $<0.001$ \\
\hline Dyslipidaemia & $1019(53.23)$ & $402(52.8)$ & $391(51.4)$ & $226(57.7)$ & 0.124 \\
\hline Prior stroke & $107(5.6)$ & 69(9.1) & $37(4.9)$ & $1(0.3)$ & $<0.001$ \\
\hline Peripheral vascular disease & $48(2.50)$ & $23(3.0)$ & $15(2.0)$ & $10(2.6)$ & 0.422 \\
\hline Chronic kidney disease & $397(20.74)$ & 104(13.6) & $229(30.2)$ & $64(16.3)$ & $<0.001$ \\
\hline \multicolumn{6}{|l|}{ Previous medical history } \\
\hline Prior Ml & $310(16.2)$ & $80(10.5)$ & $160(21.0)$ & $70(17.9)$ & $<0.001$ \\
\hline Prior $\mathrm{PCl}$ & $219(11.4)$ & $37(4.8)$ & $107(14.1)$ & $75(19.1)$ & $<0.001$ \\
\hline Prior CABG & $120(6.3)$ & $19(2.5)$ & $63(8.3)$ & $38(9.7)$ & $<0.001$ \\
\hline \multicolumn{6}{|l|}{ Clinical features on presentation } \\
\hline Admitted with chest pain & $1514(79.1 \%)$ & $635(83.4)$ & $565(74.2)$ & $314(80.1)$ & $<0.001$ \\
\hline Admitted with dyspnoea & $619(32.3 \%)$ & $186(24.4)$ & $322(42.3)$ & $111(28.3)$ & $<0.001$ \\
\hline $\mathrm{HR}<60 \mathrm{bpm}$ & $165(8.6 \%)$ & $78(10.2)$ & $61(8.0)$ & $26(6.6)$ & 0.087 \\
\hline $\mathrm{BP}<90 \mathrm{bpm}$ & $83(4.3 \%)$ & $50(6.6)$ & $31(4.1)$ & $2(0.5)$ & $<0.001$ \\
\hline \multicolumn{6}{|l|}{ Key in-hospital investigations } \\
\hline $\mathrm{HbA1C}(\%)$ & $12.7 \pm 1.7$ & $16.6 \pm 3.7$ & $9.7 \pm 1.5$ & $11.3 \pm 3.4$ & 0.182 \\
\hline S. creatinine (mg/dL) & $1.4 \pm 0.9$ & $1.4 \pm 0.9$ & $1.6 \pm 1.1$ & $1.3 \pm 0.9$ & $<0.001$ \\
\hline Cardiac marker positive & $1521(79.5)$ & $761(100.0)$ & 760(99.9) & $0(0.0)$ & $<0.001$ \\
\hline LDL- cholesterol level (mg/dL) & $98.97 \pm 41.35$ & $106.6 \pm 41.9$ & $95.2 \pm 42.0$ & $90.2 \pm 35.7$ & $<0.001$ \\
\hline LV ejection fraction (\%) & $49.48 \pm 10.92$ & $47.1 \pm 9.6$ & $49.1 \pm 11.3$ & $55.2 \pm 10.5$ & $<0.001$ \\
\hline
\end{tabular}

Table-II

Coronary angiographic findings, by ACS type

\begin{tabular}{lccccc}
\hline Key & $\mathrm{n}(\%)$ & STEMI & NSTEMI & UA & p value \\
\hline Left main stenosis $>50 \%$ & $46(2.3)$ & $13(1.7)$ & $26(3.4)$ & $5(1.3)$ & 0.026 \\
LAD $>70 \%$ & $644(33.7)$ & $314(41.3)$ & $261(34.3)$ & $69(17.6)$ & $<0.001$ \\
LCx $>70 \%$ & $519(27.1)$ & $211(27.7)$ & $236(31.1)$ & $72(18.4)$ & $<0.001$ \\
RCA $>70 \%$ & $520(27.2)$ & $241(31.7)$ & $214(28.2)$ & $65(16.6)$ & $<0.001$ \\
Ramus intermedius $>70 \%$ & $41(2.1)$ & $12(1.6)$ & $18(2.4)$ & $11(2.8)$ & 0.194 \\
Graft vessel lesion $>70 \%$ & $16(0.8)$ & $1(1)$ & $10(1.3)$ & $5(1.3)$ & $<0.001$ \\
\hline
\end{tabular}


Overall, 649 (33.9\%) patients were advised $\mathrm{PCl}$, and 198 (10.3\%) and 207 (10.8\%) were advised CABG and medical management respectively. $\mathrm{PCl}$ was performed in 505 patients $(26.4 \%)$, the majority of whom presented with STEMI (Table3). 448 (88.7\%) of those who underwent PCI received a drug eluting stent (DES).Only 47 (6.2\%) of STEMI patients underwent primary $\mathrm{PCI}, 84.1 \%$ of whom received a DES.

In-hospital outcomes and predictors of mortality: $146(7.6 \%)$ of the patients presenting with ACS expired during hospital stay (Table 4) with mortality being highest among those presenting with STEMI (10.5\%), followed by NSTEMI (8.3\%) andUA (1\%). 501 (26.2\%) patients developed LVF, significantly among NSTEMI patients (21.2\%), and 108
$(5.6 \%)$ of patients developed shock, significantly among STEMI patients. 265 (13.8\%) of patients developed acute kidney injury (AKI). The highest incidence of CKD was observed among NSTEMIpatients $(30.2 \%)$, who were also the most prone to develop AKI (16.6\%).142 (7.4\%) of patients (most frequently STEMI patients) required mechanical ventilation, of whom 38 were successfully extubated. Multivariate analysis revealed that age $>50$ years, CKD, bradycardia on admission, shock, LVF, admission with dyspnoea and STEMI were independent predictors of inhospital mortality (Table 5)

\section{Discharge medical therapy and prescriptions:}

95.5\% of ACS patients received aspirin at discharge, $93.2 \%$ in whom it was prescribed as a component of dual antiplatelet therapy (DAPT) (Table 6). Statins (82.8\%) and

Table-III

In-hospital diagnostic evaluations and treatment modalities, by acute coronary syndrome type

\begin{tabular}{|c|c|c|c|c|c|}
\hline Key & $\mathrm{n}(\%)$ & STEMI & NSTEMI & $U A$ & $p$ value \\
\hline Coronary angiography & $1022(53.4 \%)$ & $479(62.9)$ & $385(50.7)$ & $158(40.3)$ & $<0.001$ \\
\hline Advised PCl & $649(33.9)$ & $348(45.7)$ & $230(30.3)$ & $71(18.1)$ & $<0.001$ \\
\hline $\mathrm{PCl}$ on same admission & $505(26.4)$ & $297(39.0)$ & 163(21.4) & $45(11.5)$ & $<0.001$ \\
\hline Among $\mathrm{PCl}$, received drug eluting stent & $448(23.4)$ & $261(34.3)$ & $148(19.4)$ & $39(9.9)$ & $<0.001$ \\
\hline Received BMS & $108(5.6)$ & $64(8.4)$ & $36(4.7)$ & $8(2)$ & $<0.001$ \\
\hline Primary $\mathrm{PCl}$ done & $47(6.2)$ & $47(6.2)$ & - & - & - \\
\hline Advised CABG & $198(10.4)$ & $72(9.5)$ & $90(11.8)$ & $36(9.2)$ & 0.218 \\
\hline CABG done same admission & $7(0.4)$ & $1(0.1)$ & $5(0.7)$ & $1(0.1)$ & 0.214 \\
\hline Advisedmedical management & 206(11.7) & $56(8.2)$ & $83(11.9)$ & $67(17.3)$ & $<0.001$ \\
\hline
\end{tabular}

Table-IV

In-hospital event rates, by acute coronary syndrome type

\begin{tabular}{|c|c|c|c|c|c|}
\hline In-hospital event rates & & STEMI & NSTEMI & UA & $P$ value \\
\hline Shock & $107(5.6)$ & $69(9.1)$ & $37(4.9)$ & $1(0.3)$ & $<0.001$ \\
\hline Left ventricular failure & $501(26.2)$ & $209(27.5)$ & 243(31.9) & $49(12.5)$ & $<0.001$ \\
\hline Acute kidney injury & $265(13.8)$ & $113(14.8)$ & $126(16.6)$ & $26(6.6)$ & $<0.001$ \\
\hline Required mechanical ventilation & $142(7.4)$ & $71(9.3)$ & $65(8.5)$ & $6(1.5)$ & $<0.001$ \\
\hline Expired & $146(7.6 \%)$ & $79(10.4)$ & $63(8.3)$ & $4(1.0)$ & $<0.001$ \\
\hline
\end{tabular}

Table-V

Predictors of in-hospital mortality among ACS patients: Multivariate analysis

\begin{tabular}{lcc}
\hline Variable of interest & Odds Ratio $(95 \%$ Cl of OR) & p-value \\
\hline Age $(\geq 50$ yrs $)$ & $2.54(1.33-4.85)$ & 0.005 \\
Chronic kidney disease & $2.10(1.36-3.26)$ & 0.001 \\
Peripheral vascular disease & $1.22(0.44-3.39)$ & 0.708 \\
HR $<60 /$ min on admission & $1.8(1.03-3.16)$ & 0.04 \\
Shock & $16.82(10.29-27.5)$ & $<0.001$ \\
Left ventricular failure & $2.43(1.58-3.73)$ & $<0.001$ \\
Admitted on holidays & $1.88(0.96-3.67)$ & 0.06 \\
Admitted with dyspnoea & $1.80(1.15-2.8)$ & 0.009 \\
STEMl & $1.92(1.27-2.90)$ & 0.002 \\
\hline
\end{tabular}


Table-VI

Discharge medical therapy prescriptions, by acute coronary syndrome type

\begin{tabular}{lccccc}
\hline Discharge treatment & Totaln (\%) & STEMI (\%) & NSTEMI (\%) & UA (\%) & p value \\
\hline Aspirin & $1828(95.5)$ & $749(98.3)$ & $718(94.5)$ & $361(92.1)$ & $<0.001$ \\
Clopidogrel & $1627(85.0)$ & $625(82.0)$ & $670(88.2)$ & $332(84.7)$ & $<0.001$ \\
Prasugrel & $243(12.7 \%)$ & $146(19.2 \%)$ & $71(9.3 \%)$ & $26(6.6 \%)$ & $<0.001$ \\
DAPT & $1784(93.2)$ & $738(96.9)$ & $708(93.2)$ & $338(86.2)$ & $<0.001$ \\
Aspirin+ Clopidogrel & $1623(84.8)$ & $625(82.0)$ & $670(88.2)$ & $328(83.7)$ & 0.003 \\
Aspirin+ Prasugrel & $243(12.7 \%)$ & $146(19.2 \%)$ & $71(9.3 \%)$ & $26(6.6 \%)$ & $<0.001$ \\
Beta-clocker & $904(47.3)$ & $367(48.3)$ & $430(56.5)$ & $180(45.9)$ & 0.005 \\
Statin & $1464(82.8)$ & $571(83.7)$ & $568(81.4)$ & $325(83.8)$ & 0.437 \\
ACEI/ARB & $280(41.1)$ & $237(34.0)$ & $169(43.6)$ & $169(43.11)$ & 0.002 \\
Nitrate & $1349(76.3)$ & $529(77.6)$ & $547(78.4)$ & $273(70.4)$ & 0.007 \\
Trimetazidine & $1241(70.2)$ & $497(72.9)$ & $515(73.8)$ & $229(59.0)$ & $<0.001$ \\
All 4 drugs: DAPT, beta-blocker, & $207(11.7)$ & $108(15.8)$ & $59(8.5)$ & $40(10.3)$ & $<0.001$ \\
ACE-I/ARB, statin & & & & & \\
\hline
\end{tabular}

Table-VII

Comparison of characteristics of ACS patients from registries in developed and developing countries

\begin{tabular}{|c|c|c|c|c|c|c|c|c|c|c|c|c|}
\hline Registry & $\begin{array}{c}\text { Mean } \\
\text { age } \\
\text { (years) }\end{array}$ & $\begin{array}{c}\text { Sex } \\
\text { male } \\
\%)\end{array}$ & $\begin{array}{c}\mathrm{HTN} \\
\%\end{array}$ & $\begin{array}{c}\mathrm{DM} \\
\%\end{array}$ & $\begin{array}{c}\mathrm{DL} \\
\%\end{array}$ & $\begin{array}{c}\text { Smok } \\
\text { ing } \\
\% \\
\end{array}$ & $\begin{array}{c}\text { STE- } \\
\mathrm{Ml} \\
\% \\
\end{array}$ & $\begin{array}{c}\text { NST- } \\
\text { EMI } \\
\% \\
\end{array}$ & $\begin{array}{c}\text { UA } \\
\%\end{array}$ & $\begin{array}{c}\text { CAG } \\
\text { rates } \\
\% \\
\end{array}$ & $\begin{array}{c}\mathrm{PCl} \\
\text { rates } \\
\% \\
\end{array}$ & $\begin{array}{c}\text { PPCl } \\
\text { rates } \\
\% \\
\end{array}$ \\
\hline Bangladesh & $57.8 \pm 12.1$ & 71.4 & 74.2 & 68.9 & 53.2 & 25.8 & 39.8 & 39.7 & 20.5 & 53.4 & 26.6 & 6.2 \\
\hline Kerala ACS Registry 8 & $60.4 \pm 12.1$ & 77.4 & 48.4 & 37.6 & $\mathrm{~N} / \mathrm{A}$ & 34.4 & 37 & 31 & 32 & 19.5 & 11.9 & $\mathrm{~N} / \mathrm{A}$ \\
\hline CREATE Registry ${ }^{7}$ & $57.5 \pm 12.1$ & 76.4 & 37.7 & 30.4 & N/A & 40.2 & 60.6 & $39.4^{*}$ & - & 23.2 & 7.5 & \\
\hline Gulf RACE Registry ${ }^{16}$ & $55 \pm 12$ & 76 & 46 & 38 & 31 & 45 & 39 & 32 & 29 & 22 & N/A & 7 \\
\hline SPACE Registry ${ }^{17}$ & $58 \pm 12.9$ & 77.4 & 55.3 & 58.1 & 41.4 & 32.4 & 41.5 & $58.5^{*}$ & - & 67.2 & 35.3 & 17.5 \\
\hline GRACE Registry 18-19 & $64 \pm 13$ & 72 & $50 \S$ & $21 \S$ & $35 \S$ & $62 \S$ & 30 & 25 & 38 & 55 & 40 & 18 \\
\hline Malaysian NCVDACS Registry ${ }^{11}$ & $59 \pm 12$ & 75 & 72.6 & 55 & 55.9 & 57 & 42 & 33 & 25 & 35 & 46 & 8 \\
\hline CPACS Registry, China ${ }^{14}$ & 64.4 & 67 & 59.7 & 21.2 & 32.9 & 52.3 & 43 & 11 & 46 & $56.8 \S i$ & $52.7 \S \ddot{~}$ & 16.3 \\
\hline TRACS Registry ${ }^{13}$ & $63.5+12.8$ & 67.5 & 59.5 & 50.7 & 83.2 & 32.1 & 54.9 & 33.1 & 12 & 44.3 & 42.05 & 24.7 \\
\hline ACCESS Registry 21 & 59 & 81 & 56.73 & 35.87 & 41.46 & 40.32 & 46 & $54^{*}$ & - & 57.85 & 35.29 & \\
\hline The Euro Heart Survey on ACS $(I)^{2,2}$ & 2365.2 & 67.5 & $51.6 \S$ & $21.1 \S$ & $46.8 \S$ & $63.1 \S$ & 42 & $51^{*}$ & - & $56.3 \S$ & $40.4 \S$ & 37 \\
\hline Euro Heart Survey - ACS II 23 & 64.7 & 70.1 & $50.0 \S$ & $21.4 \S$ & $43.2 \S$ & 45.6 & 47 & $48^{*}$ & - & $70.2 \S$ & $57.8 \S$ & 59 \\
\hline NCDRACTIONAR-G Registry ${ }^{24}$ & $60 \S$ & $71.3 \S$ & $62.5 \S$ & $22.7 \S$ & $52.2 \S$ & $43.7 \S$ & - & - & - & 93 & 81.5 & 83 \\
\hline
\end{tabular}

For STEMI only

* NSTE-ACS î admitted to level 3 hospital

nitrates $(76.3 \%)$ were the next most commonly prescribed class of medications after antiplatelet drugs. 367 (48.3\%) of patients with STEMI were prescribed beta-blockers. STEMI patients (15.8\%) were the most likely to receive four drug classes known to have mortality benefit after ACS (i.e. DAPT, beta-blocker, ACE-inhibitor and statin.

\section{Discussion}

To the best of our knowledge, these data represent the largest contemporary ACS registry in Bangladesh, to date.
It provides insight into the descriptive epidemiology, practice patterns and in-hospital outcomes of Bangladeshi ACS patients presenting to a tertiary cardiac centre. Table 7 represents a comparison of characteristics of ACS patients from different registries worldwide.

The mean age of our subjects was a relatively young age of $57.8 \pm 12.1$ years, which is comparable with those of the CREATEand middle eastern registries (GulfRACE and SPACE) ${ }^{7}, 16,17$, marginally lower than the Kerala ACS 
registry $^{8}$ and ACCESS registry ${ }^{21}$, but significantly younger than those of Thai ACSRegistry, GRACE, ACTION AR-G and other European registries ${ }^{13}, 18,22-24$, reflecting the younger presentation of ACS among Bangladeshis.

Approximately three-fourths of our ACS population was male, an observation seen across all ACS registries worldwide. In terms of risk factor distribution, $74.2 \%$ had hypertension, $68.9 \%$ had diabetes, $53.2 \%$ had dyslipidaemia and $25.8 \%$ had a history of smoking. These rates of smoking may be underestimated owing to lack of data in some patient records. Hypertension, diabetes and dyslipidaemia showed much greater incidence in our population in comparison to other Asian and Western registries. In fact, the incidence of diabetes we report may be one of the highest rates of diabetes in an ACS population, which is triple the rates reported in the multinational GRACE registry ${ }^{18,19}$, and almost double the rates reported in Indian studies ${ }^{7,8}$. The presence of CKD, an additional risk factor contributing to poor outcome, was as high as $20.7 \%$ in this ACS population, possibly linked to the high prevalence of concomitant diabetes and hypertension. CKD has not been welldocumented in other ACS registries, however, we found in our study that CKD posed significant mortality risk (odds ratio 2.1, $\mathrm{p}<0.001$ ). The clustering of these co-morbidities may be responsible for ACS presentation at a much younger age in our population, as well as for the marginally increased overall mortality rate observed in our registry. Similarly, in a sub analysis of Gulf RACE registry, diabetic patients presenting with ACS were more likely to have a clustering of additional co-morbidities and were at risk of more adverse non-fatal hospital outcomes ${ }^{31}$.

In this study, STEMI patientswere younger than those with NSTE-ACS. They had fewer risk factors, and a less frequent history of prior cardiac disease or intervention; they were, however, more often smokers, and significantly higher inhospital mortality rate, compared to NSTEMI. These findings reflect those observed in regional registries such as CREATE, Kerala ACS and ACCESS $7,8,21$, as well as those from high income countries (AR-G registries-ACS II registries $)^{22-24}$, reflecting a pattern of a generally greater co-morbidities and higher number of risk factors among NSTE-ACS patients.

There was almost equal presentation of STEMI and NSTEMI as admission diagnosis, in this series. This is in contrast to mostAsian registries and the GRACE registry, where STEMI was the most common presentation of $\mathrm{ACS}^{7,8,11,13,16}$. In both the Euro Heart Surveys, SPACE registry and a more contemporary Indian study, NSTEMI was the more common diagnosis $^{9,16,22,23} .53 .4 \%$ of all ACS patients in our registry underwent coronary angiography. This is comparable with
GRACE and Euro-Heart SurveryACS-Iregistry 18, 22, 23 , and significantly higher in comparison to Indian registries, as well as Gulf RACE $7,8,16$. The higher angiographic rates could largely be driven by the relatively more affluent socioeconomic status of patients being admitted in this hospital, as well as the more contemporary nature of our data. APCI rate of $26.6 \%$ is also higher than other registries in the region, albeit substantially lower than Middle Eastern and Western registries (Table7). $43 \%$ of patients who underwent $\mathrm{PCI}$ had presented with STEMI, among whom only $6.2 \%$ underwent primary $\mathrm{PCl}$. This relatively lower rate is comparable to Gulf RACE and Malaysian NCVD ACS registry ${ }^{11,16}$, but is staggeringly lower than rates of high income countries. Explanations for this lower rate are multifactorial: it may be due to the unavailability of primary $\mathrm{PCl}$ facilities during night hours, and also due to educational and cultural factors such as patient refusal to undergo an 'invasive' procedure immediately after admission, preferring a more conservative approach in the initial days of admission.

However, a much higher number of overall STEMI patients undergoing $\mathrm{PCl}$ were given a DES (84.3\%), in comparison to $39 \%$ in ACCESS and $26 \%$ in GRACE ${ }^{18,21}$. Of the $5.5 \%$ in whom primary $\mathrm{PCI}$ was done, $85.4 \%$ received a DES. This may reflect the more contemporary nature of our data and the increased use of DES over time.

93.2\% of our patients received DAPT at discharge, among whom $85 \%$ were given clopidogrel, and $12.7 \%$ prasugrel as P2Y12 blocker. Compared with the Kerala registry, patients in our study were more likely to receive most key evidencebased ACS medications on discharge prescriptions, except beta-blockers, which were prescribed less (47.3\% vs $62.7 \%$ in Kerala registry $)^{8}$. The lower rates of prasugrel reflect a new entry of the drug into the local arena;ticagrelor was unavailable in the country during the time of this study.

The overall in-hospital mortality rate of $7.6 \%$ is comparable to data from CREATE ${ }^{7}$ and the Malaysian NCVD registry ${ }^{11}$, but higher than those observed in registries from high income countries, and the Kerala registry ${ }^{8}$. This may be due to the increased prevalence and clustering of more than one cardiovascular risk factor among study subjects. Although NSTE-ACS patients had worse prior histories and more risk factors, their mortality was lower than STEMI patients, reflecting similar observations of prior studies ${ }^{21}$.

\section{Limitations}

Due to the retrospective nature of the study, the data were observational, which limits our ability to evaluate causation, and correlation to prominent ACS risk scores for predicting outcomes such as the GRACE risk score and Thrombolysis in Myocardial Infarction (TIMI) risk score. Due to logistical 
reasons, data collected were of in-patients, and do not take into account the highest risk patients who expired in the emergency room (ER) prior to admission; as such, mortality rates may be underestimated. The absence of follow up data and post-discharge event rates are an additional limitation.The socio-economic status of the patients was not documented, a factor that largely influences patients' ability to finance coronary angiography and $\mathrm{PCl}$, both of which are important predictive factors access to health care and consequent outcome. Also, as data was limited to the capital city where patients finance care by themselves, it may not be geographically or socioeconomically representative on the entire Bangladeshi population, in terms of risk factor and mortality rates.

\section{Conclusion}

To the best of our knowledge, this study represents one of the larger single centre analyses of ACS patients in Bangladesh thus far. Bangladeshi subjects with ACS tend to be younger, with high prevalence of cardiovascular risk factors particularlydiabetes. In-hospital mortality rates were comparable to some South and East Asian registries, but higher than those of developed countries in Europe and the Americas.Management strategies were more conservative than those reported in Western populations, and there is room for further improvement in terms of guideline-directed therapy, both pharmacotherapy and interventional, in order to improve outcomes among ACS patients.

\section{References}

1. Murray CJ, Lopez AD. Alternative projections of mortality and disability by cause 1990-2020: Global Burden of Disease Study. Lancet 1997; 349(9064):1498-504.

2. Islam AKMM, Majumder AA. Coronary artery disease in Bangladesh: a review. Indian Heart $J$ 2013:65(4);424-435

3. Joshi P, Islam S, Pais P, Reddy S, Dorairaj P, Kazmi $\mathrm{K}$, et al. Risk factors for early myocardial infarction in South Asians compared with individuals in other countries. JAMA 2007;297(3):286-94.

4. Braunwald E. Unstable angina: an etiologic approach to management. Circulation 1998; 98: 2219-22.

5. Giannitsis E, Hamm C, Nef H, Katus HA. Cardiac biomarkers [Internet] The PCR-EAPCI Textbook. Available from: https://www.pcronline.com/ eurointervention/textbook/pcr-textbook/chapter/ ?chapter_id=79.

6. Chew DP, French J, Briffa TG, Hammett CJ, Ellis CJ, Ranasinghe I, et al. Acute coronary syndrome care across Australia and New Zealand: the SNAPSHOT ACS study. Med J Aust 2013;199(3):185-91.

7. Xavier D, Pais P, Devereaux PJ, Xie C, Prabhakaran $\mathrm{D}$, Reddy KS, et al, CREATE registry investigators. Treatment and outcomes of acute coronary syndromes in India (CREATE): a prospective analysis of registry data. Lancet 2008;371(9622):1435-42

8. Mohanan PP, Mathew R, Harikrishnan S, Krishnan MN, Zachariah G, Joseph J, et al; Kerala ACS Registry Investigators. Presentation, management, and outcomes of 25748 acute coronary syndrome admissions in Kerala, India: results from the Kerala ACS Registry. Eur Heart J 2013;34(2):121-9.

9. Isezuo S, Subban V, Krishnamoorthy J, Pandurangi UM, Janakiraman E, Kalidoss L, et al. Characteristics, treatment and one-year outcomes of patients with acute coronary syndrome in a tertiary hospital in India. Indian Heart J 2014;66(2):156-63.

10. Chin SP, Jeyaindran S, Azhari R, Wan Azman WA, Omar I, Robaayah Z, et al. Acute coronary syndrome (ACS) registry - leading the charge for national cardiovascular disease (NCVD) database. Med J Malaysia 63 (Suppl. C), 29-36.

11. Ahmad WAW, Zambahari R, Ismail O, Sinnadurai J, Rosman A, Piaw CS, et al. Malaysian National Cardiovascular Disease Database (NCVD) - Acute Coronary Syndrome (ACS) registry: How are we different? Global Heart 2011;6(3):81-89.

12. Srimahachota $S$, Kanjanavanit $R$, Boonyaratavej $S$, Boonsom W, Veerakul G, Tresukosol D; TACSR Group. Demographic, management practices and inhospital outcomes of Thai Acute Coronary Syndrome Registry (TACSR): the difference from the Western world. J Med Assoc Thai 2007;90Suppl 1:1-11.

13. Srimahachota $S$, Boonyaratavej $S$, Kanjanavanit R, Sritara P, Krittayaphong R, Kunjara-Na-ayudhya R, et al; TR ACS Group.Thai Registry in Acute Coronary Syndrome (TRACS)—an extension of Thai Acute Coronary Syndrome registry (TACS) group: lower inhospital but still high mortality at one-year. J Med Assoc Thai 2012;95(4):508-18.

14. Gao R, Patel A, Gao W, Hu D, Huang D, Kong L, et al.; CPACS Investigators. Prospective observational study of acute coronary syndromes in China: practice patterns and outcomes. Heart 2008;94(5):554-60.

15. Chan MY, Du X, Eccleston D, Ma C, Mohanan PP, Ogita M, et al. Acute coronary syndrome in the AsiaPacific region. Int J Cardiol 2016;202:861-9. 
16. Zubaid M, Rashed WA, Al-Khaja N, Almahmeed W, Al-Lawati J, Sulaiman K, et al. Clinical presentation and outcomes of acute coronary syndromes in the gulf registry of acute coronary events (Gulf RACE). Saudi Med J 2008;29(2):251-5.

17. Alhabib KF, Hersi A, Alfaleh $\mathrm{H}$, Alnemer K, Alsaif $\mathrm{S}$, Taraben A, et al. Baseline characteristics, management practices, and in-hospital outcomes of patients with acute coronary syndromes: Results of the Saudi project for assessment of coronary events (SPACE) registry. J Saudi Heart Assoc 2011;23(4):233-9.

18. Fox KA, Goodman SG, Klein W, Brieger D, Steg PG, Dabbous $\mathrm{O}$, et al. Management of acute coronary syndromes. Variations in practice and outcome; findings from the Global Registry of Acute Coronary Events (GRACE). Eur Heart J 2002; 23:1177-1189.

19. Steg PG, Goldberg RJ, Gore JM, Fox KA, Eagle KA, Flather MD, et al; GRACE Investigators. Baseline characteristics, management practices, and inhospital outcomes of patients hospitalized with acute coronary syndromes in the Global Registry of Acute Coronary Events (GRACE). Am J Cardiol 2002;90(4):358-63.

20. Goodman SG, Huang W, Yan AT, Budaj A, Kennelly BM, Gore JM, et al.; Expanded Global Registry of Acute Coronary Events (GRACE 2) Investigators. The expanded Global Registry of Acute Coronary Events: baseline characteristics, management practices, and hospital outcomes of patients with acute coronary syndromes. Am Heart J 2009;158(2):193-201.e1-5.

21. ACCESS Investigators. Management of acute coronary syndromes in developing countries: acute coronary events-a multinational survey of current management strategies. Am Heart J 2011;162(5):852-859.e22.

22. Hasdai D, Behar S, Wallentin L, Danchin N, Gitt AK, Boersma $E$, et al. A prospective survey of the characteristics, treatments and outcomes of patients with acute coronary syndromes in Europe and the Mediterranean basin; the Euro Heart Survey of Acute Coronary Syndromes (Euro Heart survey ACS).Eur Heart J 2002; 23:1190-1201.

23. Mandelzweig L, Battler A, Boyko V, Bueno H, Danchin $\mathrm{N}$, Filippatos $\mathrm{G}$, et al. The second euro heart survey on acute coronary syndromes: characteristics, treatment, and outcome of patients with acs in europe and the mediterranean basin in 2004. Eur Heart J 2006; 27:2285-2293
24. Roe MT, Messenger JC, Weintraub WS, Cannon CP, Fonarow GC, Dai D, et al. Treatments, trends, and outcomes of acute myocardial infarction and percutaneous coronary intervention. J Am Coll Cardiol 2010; 56:254-263.

25. Yan AT, Yan RT, Tan M, Fung A, Cohen EA, Fitchett $\mathrm{DH}$, Langer A, et al.; Canadian Acute Coronary Syndromes 1 and 2 Registry Investigators. Management patterns in relation to risk stratification among patients with non-ST elevation acute coronary syndromes. Arch Intern Med 2007;167(10):1009-16.

26. Aliprandi-Costa B, Ranasinghe I, Turnbull F, Brown A, Kritharides $L$, Patel $A$, et al. The design and rationale of the Australian Cooperative National Registry of Acute Coronary care, Guideline Adherence and Clinical Events (CONCORDANCE). Heart Lung Circ 2013;22(7):533-41.

27. Akanda AK, Ali Z, Sayami LA, Huda RM, Debnath L, Hossain MA, et al. In-Hospital Outcomes of Patients with Acute Myocardial Infarction - An Analysis of Two Age Groups. J Cardiol Clin Res 2015; 3(1): 1042.

28. Selim S, Rahman R, Yasmin R, Karim N, Chowdhury $\mathrm{SH}$, Lona $\mathrm{H}$, et al. Risk factors of acute coronary syndrome among Bangladeshi people. Mymensingh Med J 2013;22(3):513-21.

29. Karim MA, Majumder AA, Islam KQ, Alam MB, Paul $\mathrm{ML}$, Islam MS, et al. Risk factors and in-hospital outcome of acute ST segment elevation myocardial infarction in young Bangladeshi adults. BMC Cardiovasc Disord 2015; 15: 73.

30. Cannon CP, Brindis RG, Chaitman BR, Cohen DJ, Cross JT Jr, Drozda JP Jr, et al. 2013 ACCF/AHA key data elements and definitions for measuring the clinical management and outcomes of patients with acute coronary syndromes and coronary artery disease: a report of the American College of Cardiology Foundation/American Heart Association Task Force on Clinical Data Standards (Writing Committee to Develop Acute Coronary Syndromes and Coronary Artery Disease Clinical Data Standards). Circulation 2013;127(9):1052-89.

31. Shehab A, Al-Dabbagh B, Almahmeed W, Bustani N, Agrawal A, Yusufali A, et al. Characteristics, Management, and In-Hospital Outcomes of Diabetic Patients with Acute Coronary Syndrome in the United Arab Emirates. Scientific World Journal 2012; 2012:698597 